\title{
PRODUCT ATTRIBUTE DESIGN USING AN AGENT-BASED SIMULATION OF AN ARTIFICIAL MARKET
}

\author{
Kim, S. T.; Hong, S. R. \& Kim, C. O. \\ Yonsei University, Department of Information and Industrial Engineering, \\ 50 Yonsei Ro, Seodaemun-Gu, Seoul 120-749, Republic of Korea \\ E-Mail: kimco@yonsei.ac.kr
}

\begin{abstract}
New product development is a high-risk decision-making problem in which similar products compete with each other to expand their market shares. Brand-level diffusion predictions can help product design managers to analyse how product attribute specifications impact total market shares, which can, in turn, aid managers in choosing the designs that yield maximum profits. In this paper, we develop a product attribute design method in which an artificial market consisting of consumer agents in an interaction network is created to simulate the diffusion process of products, and a genetic algorithm is integrated with the artificial market to support the product design decision-making process. The contribution of this research is that the predicted market response to product alternatives is incorporated into the product design optimisation. Two empirical experiments were conducted on the Korean laptop computer market to demonstrate the potential of this integrated method. Preliminary experiment showed that our prediction diffusion curves had an average error of $3.04 \%$. In the primary experiment, five designs were recommended, and a comparison with the 31 best-selling laptop computers resulted in an average error of less than $8 \%$ when the "Price" attribute was excluded.

(Received in July 2013, accepted in March 2014. This paper was with the authors 2 months for 1 revision.)
\end{abstract}

Key Words: Product Attribute Design, Agent-Based Simulation, Artificial Market, Product Diffusion, Genetic Algorithm

\section{INTRODUCTION}

In new product design, the managerial decision-maker has many design options for the product attributes (e.g., the CPU speed, the display size, and the hard disk capacity of a laptop computer). Thus, to minimise failure risk for a new product, it is imperative that the decisionmaker can forecast the potential market share (or sales volume) of each design alternative, assuming that other companies will launch competing products of good quality [1]. However, the dynamics of the current high-tech product market are now more difficult to predict than ever. Products have short lifecycles because new products enter the market rapidly, word-ofmouth information regarding competing products changes and spreads quickly via the Internet and the mass media, and diverse consumer demands result from the differing perceptions of consumers of the importance of product attributes and the varying degrees of sensitivity to word-of-mouth information. Thus, an integrated approach of "what-if" diffusion analysis to design alternatives and a method of seeking an optimal design with minimum development risk have become essential components of the development process of new products.

In this paper, we develop an agent-based artificial market, which is a product diffusion model that can forecast diffusion amounts (or market shares) of competing brand-level products without historical sales data. In the model, each agent represents a consumer, and a set of agents along with their social interaction network represents an artificial market. Each consumer agent simulates a consumer's product choice process. The agent chooses among competing products primarily by using an individual product evaluation in which the agent reviews professional attribute-by-attribute product ratings that are published on the Internet or in magazines. The agent then formulates its own weighting of the product attributes and re- 
evaluates the ratings. The agent also considers product evaluation information from neighbours, which is delivered through the social interaction network. Then, the agent aggregates the two pieces of information using its own degree of sensitivity to the neighbours' evaluation and probabilistically determines the final product adopted from the aggregated product information. We formulate this product choice process using a fuzzy multi-attribute utility model.

The process of product attribute design is very costly and time-consuming because product attributes have multiple levels, resulting in an extremely large number of attribute combinations. To solve this problem efficiently, we develop a product attribute design method in which the artificial market is integrated with a genetic algorithm to find the best attribute design for the product. The genetic algorithm creates an initial set of competing design options, called a population, the artificial market estimates the market shares of the design alternatives while considering the word-of-mouth effect, and the genetic algorithm creates a more competitive population of design alternatives using the estimated diffusion results. This step is iterated until the most competitive design in terms of market shares is found.

The remainder of this paper is organised as follows. In section 2, the literature on product diffusion models and existing optimal product design methods is reviewed. In section 3, an agent-based artificial market and a product attribute design based on a genetic algorithm are presented. In section 4, the performance of the developed approach is evaluated using market data for laptop computers in South Korea. Conclusions are presented in section 5.

\section{RELATED RESEARCH}

Agent-based models have emerged as a computational tool with which to explain and analyse complex systems at the micro-level [2], including consumer markets [3-5]. Agent-based models imitate natural market dynamics by specifying individual product choice processes and implementing word-of-mouth information, which is fed back to the individual decisionmaking process of potential consumers $[6,7]$. This approach supports simulations of various "what-if" scenarios in artificial markets, the results of which can be used for decision support [3, 7-9]. Kim et al. [3] estimated the automobile market share in a country by using an agentbased diffusion model. In this model, a consumer is assumed to choose a product using a deterministic criterion and to purchase the product at a randomly selected time over a certain time interval. Delre et al. [7] used agent-based models to study the effects of the timing and targeting decisions of an advertising campaign on the diffusion curves of different categories of durable products. Khouja et al. [8] developed a model for determining optimal prices and rebate values. The authors investigated the impact of different consumer perceptions and experiences with rebates on the profitability of rebates. Schramm et al. [9] used agent-based modelling for a product market with consumer and brand agents. The authors confirmed that the agent-based model could support decision-making at the brand level and provide insight for brand managers.

Recently, product design issues have been considered from an engineering perspective. Novak [10] introduced an intelligent knowledge base module for providing decision support in product design. Rihar et al. [11] developed a two-level structure to realise products simultaneously. Anisic et al. [12] presented an application tool for assembly, manufacturing and environmental protection that was incorporated into commercial software for product design improvement. Skec et al. [13] created a method that identifies and categorises risks in product development to enhance the understanding of various categories of risks in product development.

Our research links engineering product design to marketing. Determining the attribute levels for a new product is an NP-hard problem because the number of possible combinations of 
attribute levels increases exponentially with the numbers and levels of attributes [14]. To minimise the risk of failure of a newly launched product, the best attribute design, among many alternatives, that satisfies various consumers' preferences should be found during the product development process. Conjoint analysis $[14,15]$ and fuzzy multi-attribute decision techniques [16-18] have been introduced to describe consumers' preferences. Optimisation techniques, such as genetic algorithms [15], Lagrangian relaxation with a branch and bound algorithm [19], and particle swarm optimisation [20,21], which are all associated with preference measures, have been applied to determine the combination of product attributes that maximises a company's expected profit or the consumers' total utility.

\section{PRODUCT ATTRIBUTE DESIGN}

\subsection{Agent-based simulation of artificial market}

Fig. 1 is an overview of the artificial market of consumer agents and the developed product choice process of a consumer agent. In the artificial market, the nodes and links correspond to consumer agents and friendships, respectively. The artificial market of consumer agents is constructed using a small-world network structure [22]. Fig. 1 shows that the small-world network has a ring lattice form in which every node is linked to its neighbours with a fixed degree of connectivity, except that a fraction of links are rewired to randomly selected nodes.

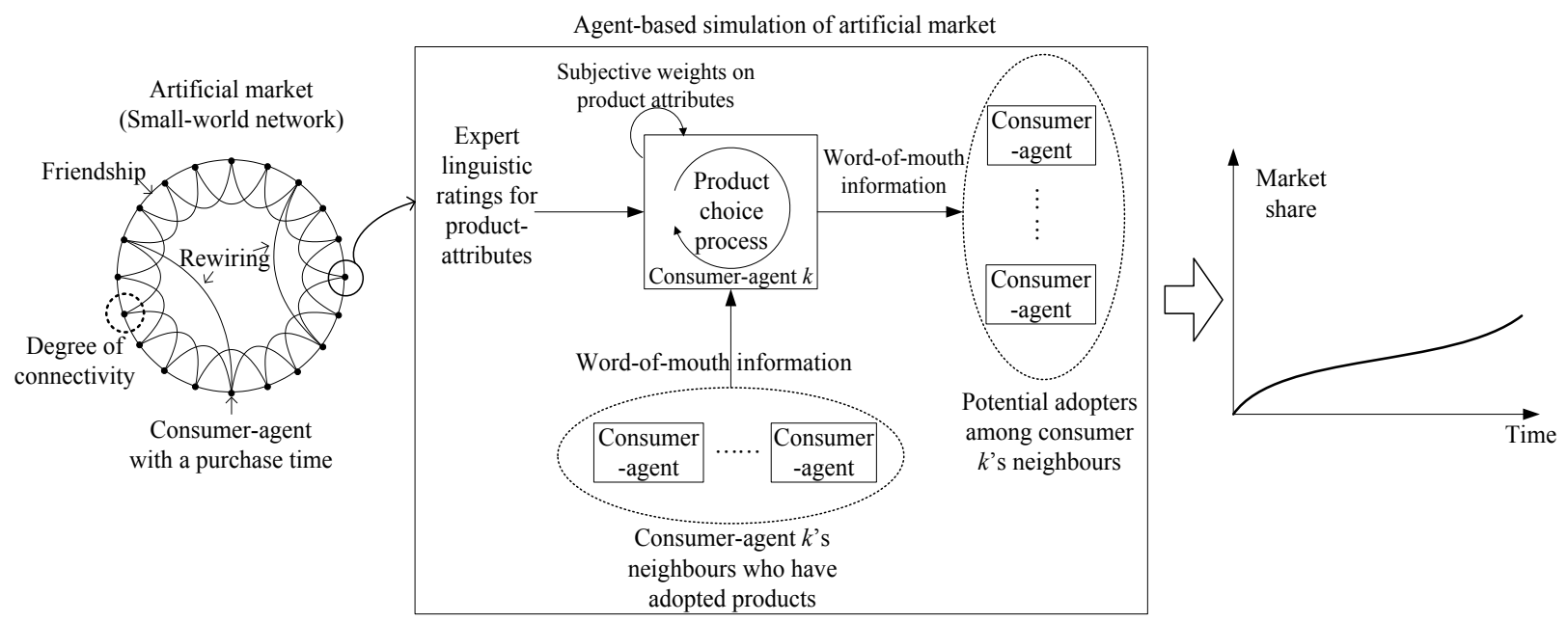

Figure 1: Artificial market simulation and developed product choice process of a consumer agent.

Empirical evidence has shown that the small-world network structure can represent many types of real social networks, including consumer interaction structures [6]. Each consumer agent has a product purchase time. We assign product purchase times to the consumer agents using a shifted Gompertz distribution, as suggested by Bemmaor \& Lee [23]. At the initialisation stage of the model, this distribution is used to randomly assign a purchase time to each consumer agent. People typically express their opinion in linguistic terms. Our model accounts for this preference and includes three types of linguistic variables: expert ratings of product attributes, consumers' subjective weights for product attributes, and degrees of sensitivity to word-of-mouth information. Experts can evaluate an attribute level using different linguistic terms (e.g., good or very good). Thus, we collect linguistic ratings for each attribute level from multiple experts to construct an empirical distribution for each attribute level. When running the model, a small portion of consumers (e.g., 1-3\% of consumer agents) play the role of experts (called innovators) and assign linguistic ratings using the empirical 
attribute-level distributions. The remaining consumers are then allowed to randomly access one of the expert's ratings.

The subjective weights for the product attributes and the degree of sensitivity to word-ofmouth information are acquired using a questionnaire. We use five linguistic terms (see Table I) that are frequently used metrics in many applications. Each linguistic term is then mapped to a triangular fuzzy number to represent the vagueness of the linguistic evaluation in a formal manner. Table I shows the linguistic variables, the linguistic terms, and the triangular fuzzy numbers. The data collected from the questionnaire are used to construct empirical distributions, namely a weight distribution for each product attribute and a sensitivity degree distribution for word-of-mouth information. The empirical distributions are used to assign weights for the consumer agents to the product attributes and the degree of sensitivity to word-of-mouth information.

Table I: Linguistic variables, linguistic terms, and triangular fuzzy numbers.

\begin{tabular}{|c|c|c|c|c|c|}
\hline Linguistic variable & \multicolumn{5}{|c|}{ Linguistic term } \\
\hline Attribute rating & $\begin{array}{c}\text { Poor } \\
(\mathrm{P})\end{array}$ & $\begin{array}{c}\text { Fair } \\
(\mathrm{F})\end{array}$ & $\begin{array}{c}\text { Good } \\
(\mathrm{G})\end{array}$ & $\begin{array}{c}\text { Very good } \\
(\mathrm{VG})\end{array}$ & $\begin{array}{c}\text { Excellent } \\
(\mathrm{E})\end{array}$ \\
\hline Weight of attribute & $\begin{array}{c}\text { Very low } \\
(\mathrm{VL})\end{array}$ & $\begin{array}{c}\text { Low } \\
(\mathrm{L})\end{array}$ & $\begin{array}{c}\text { Medium } \\
(\mathrm{M})\end{array}$ & $\begin{array}{c}\text { High } \\
(\mathrm{H})\end{array}$ & $\begin{array}{c}\text { Very high } \\
(\mathrm{VH})\end{array}$ \\
\hline $\begin{array}{c}\text { Sensitivity to word-of- } \\
\text { mouth information }\end{array}$ & $\begin{array}{c}\text { Very weak } \\
(\mathrm{VW})\end{array}$ & $\begin{array}{c}\text { Weak } \\
(\mathrm{W})\end{array}$ & $\begin{array}{c}\text { Normal } \\
(\mathrm{N})\end{array}$ & $\begin{array}{c}\text { Strong } \\
(\mathrm{S})\end{array}$ & $\begin{array}{c}\text { Very strong } \\
(\mathrm{VS})\end{array}$ \\
\hline $\begin{array}{c}\text { Triangular fuzzy number } \\
\tilde{a}=\left(a^{1}, a^{2}, a^{3}\right)\end{array}$ & $(0,0,0.3)$ & $(0.1,0.3,0.5)$ & $(0.3,0.5,0.7)$ & $(0.5,0.7,1.0)$ & $(0.7,1.0,1.0)$ \\
\hline
\end{tabular}

Let us assume that $m$ competing products of $p_{i}(i=1,2, \ldots, m)$ are in an artificial market and that a potential consumer agent $k$ evaluates the products based on $n$ attributes of $d_{j}$ $(j=1,2, \ldots, n)$. Let $\tilde{r}_{i j}$ be an expert's linguistic rating of the attribute $d_{j}$ of the product $p_{i}$ that is accessed by the consumer agent $k$. Furthermore, let $\widetilde{w}_{j}^{k}(j=1,2, \ldots, n)$ be the weight of the product attribute $d_{j}$ for consumer agent $k$. For the product $p_{i}(i=1,2, \ldots, m)$, the consumer agent $k$ accepts the expert's evaluation $\widetilde{r}_{i j}$ according to the weight $\widetilde{w}_{j}^{k}$. This process can be modelled as a product of the two triangular fuzzy numbers $\tilde{r}_{i j}$ and $\tilde{w}_{j}^{k}$, which can be regarded as the partial utility of the product $p_{i}$ with respect to the attribute $d_{j}$. However, $\tilde{r}_{i j}$ and $\widetilde{w}_{j}^{k}$ are linguistic ratings that are represented as triangular fuzzy numbers: thus, a fuzzy operation is required to multiply these ratings. We use the graded mean integration representation method [24], which is easier to understand and enables the fuzzy number multiplication to be performed relatively simply. In this method, a fuzzy number $\tilde{a}=\left(a^{1}, a^{2}, a^{3}\right)$ is converted into a crisp value according to $a=\left(a^{1}+4 a^{2}+a^{3}\right) / 6$ (see Chou [24] for details). With this simple defuzzification method, we obtain a defuzzified value $x_{i j}^{k}=\left(r_{i j}{ }^{1}+4 r_{i j}{ }^{2}+r_{i j}{ }^{3}\right) / 6 \times\left(w_{j}^{k 1}+4 w_{j}^{k 2}+w_{j}^{k 3}\right) / 6$. The value of $x_{i j}^{k}$ represents the personalised partial utility of the product $p_{i}$ with respect to the product attribute $d_{j}$.

Consumer agents respond differently to word-of-mouth information flowing from the artificial market. Let $\tilde{\alpha}_{k}$ be the linguistic sensitivity degree of the consumer agent $k$ to wordof-mouth information. The fuzzy triangular number corresponding to $\tilde{\alpha}_{k}$ is also converted into a crisp number, which is denoted by $\alpha_{k}$. The consumer agent $k$ aggregates the personalised partial utility $x_{i j}$ and the word-of-mouth information flowing from the artificial market with the sensitivity degree $\alpha_{k}$ as follows: 


$$
\bar{x}_{i j}^{k}=\left(1-\alpha_{k}\right) x_{i j}^{k}+\alpha_{k} \frac{\sum_{l \in L_{k}}^{{ }^{\prime}} \bar{x}_{i j}^{l}}{\left|L_{k}\right|}(i=1,2, \ldots, m \text { and } j=1,2, \ldots, n),
$$

where $L_{k}$ is the set of the consumer agent $k$ 's neighbours who purchased products. In this equation, we assume that consumer agent $k$ trusts each neighbour equally. The value of $\bar{x}_{i j}^{k}$ represents the agent's final partial utility of the product $p_{i}$ with respect to the attribute $d_{j}$. This value reflects a personalised evaluation $x_{i j}^{k}$ by $100\left(1-\alpha_{k}\right) \%$ and the evaluation of the neighbouring adopters by $\alpha_{k} \%$. The total utility of the consumer agent $k$ for the product $p_{i}$ is $\sum_{j=1}^{n} \bar{x}_{i j}^{k}$. We showed in a previous study [3] that product utility modelling using eq. (1) could effectively predict the market share of an automobile market.

Note that at the initialisation stage of the model, a shifted Gompertz distribution is used to assign the purchase time of consumer agent $k$. At the beginning of the simulation, the consumer agent $k$ updates the partial utility $\bar{x}_{i j}^{k}$ with word-of-mouth information that can change over time. At the purchase time in the simulation, the consumer agent $k$ chooses a product using the following multinomial logit model:

$$
P\left(\text { agent } k \text { chooses product } p_{i}\right)=\frac{\exp \left(\sum_{j=1}^{n} \bar{x}_{i j}^{k}\right)}{\sum_{l=1}^{m} \exp \left(\sum_{j=1}^{n} \bar{x}_{l j}^{k}\right)}, i=1,2, \ldots, m .
$$

After adopting a product, the consumer agent $k$ propagates the partial utility $\bar{x}_{i j}^{k}$ $(j=1,2, \ldots, n)$ of all of the competing products $(i=1,2, \ldots, m)$ to the neighbours who did not buy products. As the simulation proceeds, the product information created by the product adopters gradually spreads throughout the social network of the consumer agents (i.e., the artificial market) such that the market shares (i.e., diffusion amounts) of competing products can be assessed over time using the model.

\subsection{Genetic algorithm}

We assume that the product attributes $d_{j}(j=1,2, \ldots, n)$ have discrete levels. A product design is denoted as the vector $\mathbf{d}=\left(d_{1}, \ldots, d_{n}\right)$. When the genetic algorithm generates the design options $\mathbf{d}_{l}=\left(d_{1}, \ldots, d_{n}\right), l=1, \ldots, P$, where $P$ is the population size of the genetic algorithm, the artificial market converts these alternatives into linguistic forms $\mathrm{d}_{l}=\left(\widetilde{d}_{1}, \ldots, \widetilde{d}_{N}\right), l=1, \ldots, P$ and generates the corresponding diffusion curves. The outputs of the artificial market represent the market shares of the design alternatives. The diffusion results are used as fitness values $\left(f\left(\mathbf{d}_{1}\right), \ldots, f\left(\mathbf{d}_{P}\right)\right)$ depending on which design alternatives are constructed for the subsequent population using the genetic operators of selection, crossover, and mutation.

A population of the genetic algorithm consists of design alternatives, each of which is defined as a string $S_{l}$ for a design alternative $\mathbf{d}_{l}=\left(d_{1}, \ldots, d_{n}\right)$. The string $S_{l}$ contains substrings $s_{j}(j=1,2, \ldots, n)$ that correspond to each product attribute $d_{j}$. Because each attribute $d_{j}$ can have $\left|d_{j}\right|$ levels, the substring $s_{j}$ has $\left|d_{j}\right|$ elements with binary values $(0$ or 1$)$.

The genetic algorithm generates the next population by applying the three genetic operators to strings (or design alternatives) of the current population. The fitness value $f\left(\mathbf{d}_{l}\right)$ of design alternative $\mathbf{d}_{l}$ is the market share that is collected at the end of the diffusion. Half of the current strings $(P / 2)$ survive in the next population according to the survival probability $P\left(\mathbf{d}_{l}\right)$ that is defined in eq. (3). This selection rule is referred to as an elitist strategy and has been shown to work well for various applications [15]. 


$$
P\left(\mathbf{d}_{l}\right)=f\left(\mathbf{d}_{l}\right) / \sum_{k=1}^{P} f\left(\mathbf{d}_{k}\right)
$$

\section{EXPERIMENTS AND ANALYSIS}

\subsection{Setup}

We investigated the attribute design of laptop computers in the Korean market. The following product attributes were considered in the experiments: the CPU speed, the display size, the HDD (hard disk drive) size, the memory size, the battery duration, the weight, and the price. Sales data from February 2010 to March 2011 were obtained from a Korean online shopping mall (www.danawa.com). The total number of brand-level products was 866 . Using these data, we conducted a diffusion experiment and a product attribute design experiment. In these experiments, the artificial market was implemented using the NetLogo software (version 4.0.3) [25], which is a widely used agent-based modelling tool. The artificial market for laptop computers was constructed using a small-world network of 2500 consumer agents.

A questionnaire was designed to construct empirical distributions of the weights for the product attributes and the sensitivity to word-of-mouth information. The respondents were college students, IT consultants, and salespersons (aged 20 to 50 years) who had experience in using laptop computers. Table II shows the empirical distributions of the weights for the product attributes. Table III shows the empirical distribution of the degree of sensitivity to word-of-mouth information.

Table II: Empirical distributions of consumer weights for product attributes in the laptop computer market.

\begin{tabular}{|c|c|c|c|c|c|}
\hline \multirow{2}{*}{ Product attribute } & \multicolumn{5}{|c|}{ Linguistic terms } \\
\cline { 2 - 6 } & Very High & High & Medium & Low & Very low \\
\hline CPU speed & 0.3 & 0.58 & 0.1 & 0.02 & 0 \\
\hline Display size & 0.05 & 0.49 & 0.34 & 0.03 & 0 \\
\hline HDD size & 0.28 & 0.54 & 0.15 & 0.04 & 0 \\
\hline Memory size & 0.04 & 0.21 & 0.46 & 0.22 & 0.07 \\
\hline Battery duration & 0.36 & 0.38 & 0.24 & 0.01 & 0.01 \\
\hline Weight & 0.1 & 0.1 & 0.12 & 0.43 & 0.26 \\
\hline Price & 0.02 & 0.11 & 0.50 & 0.30 & 0.07 \\
\hline
\end{tabular}

Table III: Consumers' degree of sensitivity to word-of-mouth information in the laptop computer market.

\begin{tabular}{|c|c|c|}
\hline Sensitivity degree & Number of respondents & Relative frequency \\
\hline Very strong & 0 & 0.0 \\
\hline Strong & 15 & 0.15 \\
\hline Normal & 26 & 0.26 \\
\hline Weak & 48 & 0.48 \\
\hline Very weak & 12 & 0.12 \\
\hline
\end{tabular}

\subsection{Results and analysis}

The three netbooks selected accounted for $60 \%$ of the total market share of the netbooks. We used these products to calibrate the agent-based diffusion model. Table IV shows the linguistic product ratings published by an expert group for the Korean online shopping mall. The expert product evaluation and the empirical distributions for the weights of the product 
attributes and the degree of sensitivity to word-of-mouth information presented in the previous subsection were used to conduct a diffusion experiment for various small-world network structures. Four rewiring probabilities $(0.01,0.05,0.10$, and 0.25$)$ and five degrees of connectivity $(4,6,8,10$, and 20$)$ were considered. A total of 20 network structures were used.

Table IV: Product information for three laptop computers evaluated by the expert group.

\begin{tabular}{|c|c|c|c|c|c|c|c|}
\hline Product & $\begin{array}{c}\text { CPU } \\
\text { speed }\end{array}$ & HDD size & $\begin{array}{c}\text { Memory } \\
\text { size }\end{array}$ & $\begin{array}{c}\text { Display } \\
\text { size }\end{array}$ & $\begin{array}{c}\text { Battery } \\
\text { duration }\end{array}$ & Weight & Price \\
\hline $\mathrm{p} 1$ & $\mathrm{G}$ & $\mathrm{G}$ & $\mathrm{G}$ & $\mathrm{G}$ & $\mathrm{P}$ & $\mathrm{G}$ & $\mathrm{G}$ \\
\hline $\mathrm{p} 2$ & $\mathrm{G}$ & $\mathrm{F}$ & $\mathrm{G}$ & $\mathrm{F}$ & $\mathrm{VG}$ & $\mathrm{G}$ & $\mathrm{G}$ \\
\hline $\mathrm{p} 3$ & $\mathrm{G}$ & $\mathrm{G}$ & $\mathrm{G}$ & $\mathrm{G}$ & $\mathrm{VG}$ & $\mathrm{F}$ & $\mathrm{G}$ \\
\hline
\end{tabular}

The performance metric was the time-averaged market share error, which was defined as $\sum_{t=1}^{T}\left|\hat{M}_{t}-M_{t}\right| / T$, where $\hat{M}_{t}$ and $M_{t}$ are the predicted market share and the real market share for a period $t$, respectively, and $T$ is the prediction interval in weeks. To determine the $95 \%$ confidence interval, we ran the model 25 times for each consumer network structure and measured the average error. A minimum error of $2.6 \%$ was incurred for a rewiring probability of 0.1 and a degree of connectivity of 10 . The prediction errors for the 20 network structures were similar and relatively small, with an average error of $3.04 \%$. This observation indicates that our diffusion model performed well and was not very sensitive to the rewiring probability or the degree of connectivity. Fig. 2 shows the diffusion results obtained for a rewiring probability of 0.1 and a degree of connectivity of 10 .

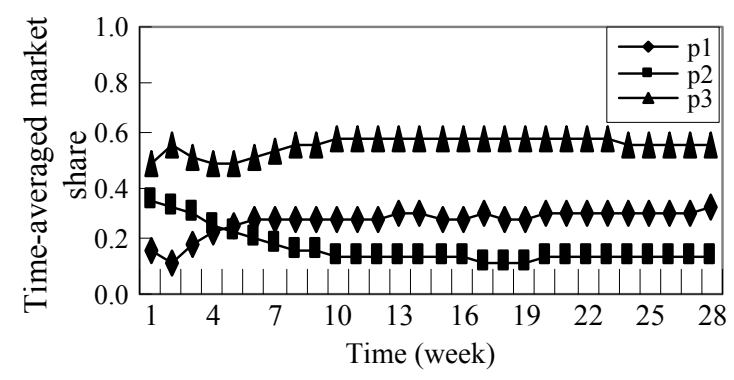

(a) Real market share paths

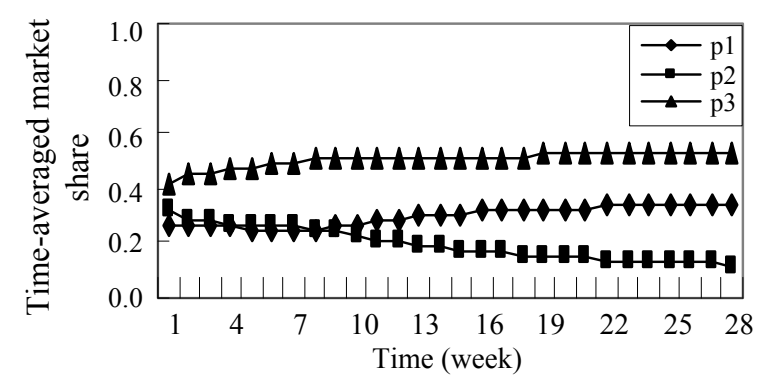

(b) Simulated market share paths

Figure 2: Market share paths of the three netbooks: real data vs. simulated data.

In the primary experiment, the performance of the developed product attribute design method was tested. The best designs that were found using the developed method were compared with those of 31 laptop computers that were selected out of the 866 laptop computers. The selected computers were ranked in the top 10 for sales volumes at least once during the study period. Table V shows the attribute specifications of the selected computers. The table shows that there were 28 distinct designs with respect to the attributes. Products with a 15-inch display, 2 GB of memory, 250 GB HDD, and a 13-hour battery also appeared to be popular in the market.

Table VI shows the ranges of the attribute levels of the laptop computers. The ranges were determined by examining the attribute levels of the 866 computers in the market. Table VI shows that there were many possible designs for a laptop computer. The design alternatives generated by the genetic algorithm had attribute levels in the given ranges. These levels had to be converted into linguistic ratings to run the diffusion simulation. Experts were given a survey to rate each attribute level using the linguistic terms of "Very high (VH)", "High (H)", "Medium (M)", "Low (L)", and "Very low (VL)". The linguistic evaluation data 
were used to construct empirical distributions for the attribute levels. Fig. 3 shows the empirical distributions for various CPU speeds. For a design alternative with a specific CPU speed, a corresponding linguistic rating was randomly obtained from the empirical distribution of that speed level.

Table V: Attribute specifications of 31 computers that were ranked within the top 10 in sales volumes at least once during the study period (February 2010 - March 2011).

\begin{tabular}{|c|c|c|c|c|c|c|c|}
\hline NO. & $\begin{array}{c}\text { Display } \\
\text { size } \\
\text { (inches) }\end{array}$ & $\begin{array}{l}\text { CPU } \\
\text { speed } \\
\text { (GHz) }\end{array}$ & $\begin{array}{l}\text { Memory } \\
\text { size } \\
\text { (GB) }\end{array}$ & $\begin{array}{l}\text { HDD size } \\
\text { (GB) }\end{array}$ & $\begin{array}{c}\text { Weight } \\
\text { (kg) }\end{array}$ & $\begin{array}{c}\text { Battery } \\
\text { duration } \\
\text { (hours) }\end{array}$ & $\begin{array}{c}\text { Price }(\times 10,000 \\
\text { KRW })\end{array}$ \\
\hline 1,2 & \multirow{4}{*}{10} & \multirow{4}{*}{1.6} & 1 & 160 & 1.5 & 5 & 60 \\
\hline $3,4,5$ & & & 1 & 160 & 1.5 & 5 & 70 \\
\hline 6 & & & 2 & 320 & 1.5 & 3 & 60 \\
\hline 7 & & & 2 & 250 & 2 & 5 & 90 \\
\hline 8 & \multirow{3}{*}{12} & 2.26 & 2 & 160 & 1.5 & 2.5 & 140 \\
\hline 9 & & 2 & 2 & 320 & 2 & 4 & 140 \\
\hline 10 & & 1.73 & 1 & 120 & 2 & 4 & 120 \\
\hline 11 & \multirow{2}{*}{13} & 2.4 & 2 & 250 & 2 & 3.5 & 230 \\
\hline 12 & & 2.4 & 2 & 320 & 2 & 3.5 & 200 \\
\hline 13 & \multirow{6}{*}{14} & 2.1 & 2 & 200 & 2.5 & 3 & 130 \\
\hline 14 & & 1.66 & 1 & 160 & 2.5 & 3 & 70 \\
\hline 15 & & 2.26 & 2 & 250 & 2.5 & 3 & 120 \\
\hline 16 & & 1.9 & 2 & 250 & 2.5 & 3 & 80 \\
\hline 17 & & 2 & 2 & 250 & 2.5 & 3 & 140 \\
\hline 18 & & 2.16 & 1 & 160 & 2.5 & 3 & 70 \\
\hline 19 & \multirow{13}{*}{15} & 2.4 & 2 & 250 & 3 & 3 & 150 \\
\hline 20 & & 2.4 & 2 & 250 & 3 & 3 & 140 \\
\hline 21 & & 1.73 & 1 & 120 & 3 & 3 & 90 \\
\hline 22 & & 1.73 & 1 & 120 & 3 & 3 & 100 \\
\hline 23 & & 2.1 & 2 & 250 & 3 & 3 & 130 \\
\hline 24 & & 2.1 & 1 & 160 & 3 & 3 & 110 \\
\hline 25 & & 1.86 & 1 & 120 & 3 & 3 & 100 \\
\hline 26 & & 2.5 & 3 & 320 & 3 & 3 & 200 \\
\hline 27 & & 2.5 & 2 & 250 & 3 & 3 & 160 \\
\hline 28 & & 2.26 & 3 & 250 & 2.5 & 3 & 120 \\
\hline 29 & & 2.26 & 2 & 250 & 3 & 3 & 140 \\
\hline 30 & & 2 & 2 & 160 & 2.5 & 3 & 90 \\
\hline 31 & & 2 & 2 & 250 & 3 & 3 & 70 \\
\hline
\end{tabular}

Table VI: Attribute level ranges for laptop computers.

\begin{tabular}{|c|c|}
\hline Attribute & Range \\
\hline CPU speed (GHz) & {$[1.0,3.0]$} \\
\hline Display size (inches) & {$[10,15]$} \\
\hline HDD size $(\mathrm{GB})$ & {$[60,400]$} \\
\hline Memory size $(\mathrm{GB})$ & {$[0.25,4]$} \\
\hline Battery duration (hours) & {$[1,7]$} \\
\hline Weight $(\mathrm{kg})$ & {$[1,7]$} \\
\hline Price $(\times 10,000 \mathrm{KRW})$ & {$[30,250]$} \\
\hline
\end{tabular}

To assess the prices of the design alternatives generated by the genetic algorithm, we conducted a regression analysis using the prices of five computer components (attributes): the 
CPU, the speed display size, the HDD size, the memory size, and the battery duration. The component prices were collected from the online shopping mall. Table VII shows the price regression models for the five attributes. The retail price of a design alternative was assumed to be the sum of the estimated component prices.

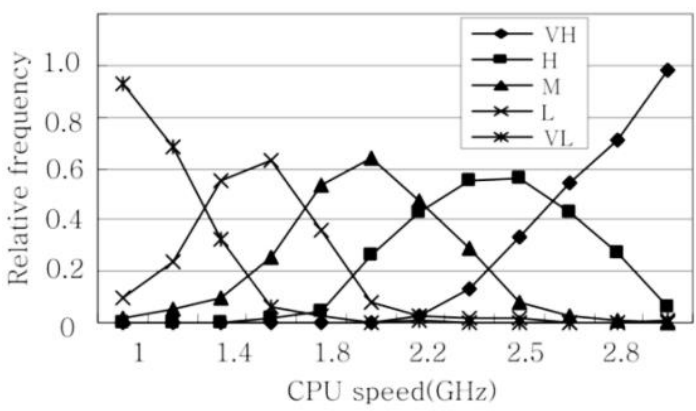

Figure 3: Empirical distributions of CPU speeds.

Table VII: Price regression models for five attributes.

\begin{tabular}{|c|c|c|c|c|c|}
\hline $\begin{array}{c}\text { Product } \\
\text { attribute }\end{array}$ & CPU speed $\left(\boldsymbol{d}_{\mathbf{1}}\right)$ & $\begin{array}{c}\text { Display size } \\
\left(\boldsymbol{d}_{\mathbf{2}}\right)\end{array}$ & $\begin{array}{c}\text { HDD size } \\
\left(\boldsymbol{d}_{\mathbf{3}}\right)\end{array}$ & $\begin{array}{c}\text { Memory size } \\
\left(\boldsymbol{d}_{\mathbf{4}}\right)\end{array}$ & $\begin{array}{c}\text { Battery } \\
\text { duration }\left(\boldsymbol{d}_{\mathbf{5}}\right)\end{array}$ \\
\hline $\begin{array}{c}\text { Regression } \\
f\left(d_{1}\right)\end{array}$ & $84 d_{1}^{3}-231 d_{1}^{2}+484$ & $40 d_{2}-153$ & $0.29 d_{3}+10.08$ & $0.012 d_{4}+11.069$ & $2.208 d_{5}+74.622$ \\
\hline $\begin{array}{c}\text { Goodness } \\
\text { of fit }\left(R^{2}\right)\end{array}$ & 0.808 & 0.828 & 0.89 & 0.763 & 0.745 \\
\hline
\end{tabular}

(Significance level: 0.05)

The population size, the crossover rate, and the mutation rate for the genetic algorithm were determined in this experiment. We considered three population sizes $(50,100$, and 150), three crossover rates $(0.1,0.2$, and 0.3$)$, and three mutation rates $(0.1,0.2$, and 0.3$)$. The agent-based diffusion simulation was time-consuming. Thus, we searched for the smallest iteration count among the 27 parameter combinations that met a termination condition. Table VIII shows the numbers of iterations for each parameter combination. A minimum of iterations were required for a population size of 100 , a crossover rate of 0.2 , and a mutation rate of 0.3 . On average, however, a population of 50 required fewer simulation runs than a population of 100 . Therefore, the genetic algorithm with a population size of 50, a crossover rate of 0.3 , and a mutation rate of 0.2 was used to search for the best design alternatives.

Table VIII: Parameter calibration results of the genetic algorithm.

\begin{tabular}{|c|c|c|c|c|c|c|c|c|c|c|}
\hline \multirow{2}{*}{\multicolumn{2}{|c|}{$\begin{array}{l}\text { Population size } \\
\text { Crossover rate }\end{array}$}} & \multicolumn{3}{|c|}{50} & \multicolumn{3}{|c|}{100} & \multicolumn{3}{|c|}{150} \\
\hline & & 0.1 & 0.2 & 0.3 & 0.1 & 0.2 & 0.3 & 0.1 & 0.2 & 0.3 \\
\hline \multirow{3}{*}{$\begin{array}{l}\text { Mutation } \\
\text { rate }\end{array}$} & 0.1 & 12 & 14 & 29 & 13 & 8 & 7 & 55 & 5 & 50 \\
\hline & 0.2 & 7 & 12 & 5 & 18 & 12 & 17 & 25 & 18 & 35 \\
\hline & 0.3 & 25 & 6 & 11 & 9 & 2 & 10 & 21 & 45 & 10 \\
\hline \multicolumn{2}{|c|}{ Average iteration number } & \multicolumn{3}{|c|}{14} & \multicolumn{3}{|c|}{10} & \multicolumn{3}{|c|}{29} \\
\hline \multicolumn{2}{|c|}{ Minimum iteration number } & \multicolumn{3}{|c|}{5} & \multicolumn{3}{|c|}{2} & \multicolumn{3}{|c|}{5} \\
\hline
\end{tabular}

We conducted five replicates of the genetic algorithm and selected the best computer design from each replicate. The specifications of the selected designs (D1-D5) are summarised in Table IX. We quantified the differences between the five selected computer designs and the 31 best-selling laptop computers, as shown in Table V. For a selected computer design and a best-selling computer, we defined the difference as $\sum_{j=1}^{n}\left\{\left|\hat{v}_{j}-v_{j}^{*}\right| / I_{j}\right\} / n$, 
where $n$ is the number of product attributes, $I_{j}$ is the range of the product attribute $d_{j}$, $\hat{v}_{j}$ is the attribute level of the selected computer design, and $d_{j}^{*}$ is the attribute level of the bestselling computer. Table IX shows that the computer design D5 exhibited the smallest difference at $7.22 \%$. The computer design D5 and the best-selling computer No. 30 were very similar in terms of their attribute levels. The other computer designs (D1-D4) had average differences of approximately $10 \%$. The total average difference of D1-D5 was $9.5 \%$.

We used a statistical regression technique to estimate the "Price" attribute of the laptop computers. We fitted the price data of the five components (attributes) of the laptop computer to predict the retail prices of the selected computer designs. However, this regression approach was not sufficiently accurate, as companies' pricing policies may result in different prices for the selected computer designs. Thus, we excluded the attribute "Price" and analysed the experimental results again. Table IX (bottom) shows that the computer design D3 exhibited the smallest difference at $7.17 \%$ and that the other designs exhibited low differences of approximately $8 \%$. The total average difference of D1-D5 was $7.84 \%$. This analysis indicates that the prediction accuracy may be increased by improving the price estimation model. Prediction accuracy is a critical property for decision support problems in uncertain situations. Thus, this experiment demonstrated the potential of our product attribute design method. We expect that managerial decision-makers working on the development of new products can use the suggested decision support paradigm to reduce the risk of product failure.

Table IX: Product attribute design results: comparison of five selected designs and 31 actual products.

\begin{tabular}{|c|c|c|c|c|c|c|c|c|c|c|c|c|c|c|c|}
\hline $\begin{array}{c}\text { Selected } \\
\text { design }\end{array}$ & D1 & & & D2 & & & D3 & & & D4 & & & D5 & & \\
\hline CPU & 2.4 & 2.26 & 2.26 & 2.6 & 2.26 & 2.4 & 2.5 & 2.26 & 2.4 & 2.2 & 2.26 & 2.4 & 1.9 & 2 & 2 \\
\hline HDD & 120 & 160 & 160 & 200 & 160 & 250 & 250 & 250 & 250 & 320 & 250 & 320 & 120 & 160 & 160 \\
\hline Display & 12 & 12 & 12 & 12 & 12 & 13 & 12 & 15 & 13 & 13 & 15 & 13 & 15 & 15 & 15 \\
\hline Memory & 2.5 & 2 & 2 & 2 & 2 & 2 & 3 & 3 & 2 & 3 & 3 & 2 & 3 & 2 & 2 \\
\hline Battery & 3.4 & 2.5 & 2.5 & 3.4 & 2.5 & 3.5 & 3.4 & 3 & 3.5 & 3.2 & 3 & 3.5 & 2.8 & 3 & 3 \\
\hline Weight & 1.6 & 1.5 & 1.5 & 1.6 & 1.5 & 2 & 1.6 & 2.5 & 2 & 1.9 & 2.5 & 2 & 2.7 & 2.5 & 2.5 \\
\hline Price & 87 & 140 & 140 & 97 & 140 & 230 & 96 & 120 & 230 & 92 & 120 & 200 & 91 & 90 & 90 \\
\hline $\begin{array}{c}\text { Average } \\
\text { difference } \\
(\%)\end{array}$ & & 10.41 & & & 9.28 & & & 10.65 & & & 9.95 & & & 7.22 & \\
\hline $\begin{array}{c}\text { Average } \\
\text { difference } \\
(\%)\end{array}$ & & & 8.13 & & & 7.17 & & & 8.33 & & & 7.22 & & & 8.35 \\
\hline $\begin{array}{c}\text { Actual } \\
\text { product } \\
\text { (see Table V) }\end{array}$ & & $\# 8$ & $\# 8$ & & \#8 & $\# 11$ & & $\# 28$ & \#11 & & $\# 28$ & $\# 12$ & & $\# 30$ & $\# 30$ \\
\hline
\end{tabular}

\section{CONCLUSION}

Insight into brand-level sales growth can be used to maximise the success probability of new products and minimise the associated risk and opportunity cost. Brand-level diffusion predictions can help product design managers analyse the impact of attribute specifications on total market shares, which can aid managers in choosing designs that maximise profits.

Advances in information technology and the emergence of Internet social network sites have profoundly altered social interaction mechanisms. Word-of-mouth information transmitted over the Internet is archived in searchable databases. Thus, the product ratings of 
previous adopters become accessible to a large number of people in the future, regardless of spatiotemporal constraints. In this paper, we developed an agent-based artificial market that focuses on the product choice processes of heterogeneous consumers while considering the word-of-mouth effect at the product attribute level. In the artificial market, the consumer agents have a heterogeneous propensity to purchase products. Each agent makes a subjective assessment of each product and decides on the utility of each product attribute by weighing the product attribute ratings from experts according to the agent's weights for each product attribute. The agent also considers the product assessments of neighbours at the attribute level. To validate the performance of the diffusion model, an empirical experiment was conducted on the Korean laptop computer market. A preliminary experiment showed that our prediction diffusion curves had an average error of $3.04 \%$.

The artificial market and a genetic algorithm were integrated to support the decisionmaking process of product attribute design. The genetic algorithm generated a population of design alternatives and the artificial market simulated their competition to estimate their market shares over time. The interaction of the two steps was repeated until the best design alternative was found. An empirical experiment conducted on the Korean laptop computer market yielded promising results, i.e., five designs were suggested, and a comparison with the 31 best-selling laptop computers in the Korean market resulted in an average error of less than eight percent when the "Price" attribute was excluded.

We anticipate that constant external shocks will require our model to be upgraded. We assumed that every consumer-agent referred to the experts' opinions at the beginning of product diffusion. We neglected several external shocks (e.g., marketing strategies, such as price discounts and promotions, changes in the experts' opinions, and operational problems) that occur inconsistently in practice. Psychological bias can also be incorporated into human product choice modelling. In particular, most consumers who choose products tend to be reference-dependent and risk averse. For example, consumers usually evaluate a new product by comparing it to the products they already use. Most consumers also perceive a wider gap when the value gained from the product being used is larger than that expected for the new product compared to when the value gained is less than the expected value, even for the same absolute difference. Prospect theory from economics may explain such human behaviour. We are currently introducing prospect theory into the agent-based artificial market.

\section{ACKNOWLEDGEMENTS}

This research was supported by the Basic Science Research Program of the National Research Foundation of Korea (NRF) and was funded by the Ministry of Education (2013R1A1A2A10013104).

\section{REFERENCES}

[1] Meade, N.; Islam, T. (2006). Modelling and forecasting the diffusion of innovation - A 25-year review, International Journal of Forecasting, Vol. 22, No. 3, 519-545, doi:10.1016/j.ijforecast. $\underline{2006.01 .005}$

[2] Macal, C. M.; North, M. J. (2010). Tutorial on agent-based modelling and simulation, Journal of Simulation, Vol. 4, No. 3, 151-162, doi:10.1057/jos.2010.3

[3] Kim, S.; Lee, K.; Cho, J. K.; Kim, C. O. (2011). Agent-based diffusion model for an automobile market with fuzzy TOPSIS-based product adoption process, Expert Systems with Applications, Vol. 38, No. 6, 7270-7276, doi:10.1016/j.eswa.2010.12.024

[4] Gunther, M.; Stummer, C.; Wakolbinger, L. M.; Wildpaner, M. (2011). An agent-based simulation approach for the new product diffusion of a novel biomass fuel, Journal of the Operational Research Society, Vol. 62, No.1, 12-20, doi:10.1057/jors.2009.170 
[5] Lee, K.; Kim, S.; Kim, C. O.; Park, T. (2013). An agent-based competitive product diffusion model for the estimation and sensitivity analysis of social network structure and purchase time distribution, Journal of Artificial Societies and Social Simulation, Vol. 16, No. 1 (http://jasss.soc.surrey.ac.uk/16/1/3.html)

[6] Alkemade, F.; Castaldi, C. (2005). Strategies for the diffusion of innovations on social networks, Computational Economics, Vol. 25, No. 1-2, 3-23, doi:10.1007/s10614-005-6245-1

[7] Delre, S. A.; Jager, W.; Bijmolt, T. H. A.; Janssen, M. A. (2007). Targeting and timing promotional activities: An agent-based model for the takeoff of new products, Journal of Business Research, Vol. 60, No. 8, 826-835, doi:10.1016/j.jbusres.2007.02.002

[8] Khouja, M.; Hadzikadic, M.; Zaffar, M. A. (2008). An agent based modeling approach for determining optimal price-rebate schemes, Simulation Modelling Practice and Theory, Vol. 16, No. 1, 111-126, doi:10.1016/j.simpat.2007.11.001

[9] Schramm, M. E.; Trainor, K. J.; Shanker, M.; Hu, M. Y. (2010). An agent-based diffusion model with consumer and brand agents, Decision Support Systems, Vol. 50, No. 1, 234-242, doi:10.1016/j.dss.2010.08.004

[10] Novak, M. (2012). Computer aided decision support in product design engineering, Technical Gazette, Vol. 19, No. 4, 743-752

[11] Rihar, L.; Kusar, J.; Gorenc, S.; Starbek, M. (2012). Teamwork in the simultaneous product realisation, Strojniski vestnik - Journal of Mechanical Engineering, Vol. 58, No. 9, 534-544, doi:10.5545/sv-jme.2012.420

[12] Anisic, Z.; Veza, I.; Suzic, N.; Sremcev, N.; Orcik, A. (2013). Improving product design with IPS-DFX methodology incorporated in PLM software, Technical Gazette, Vol. 20, No. 1, 183 193

[13] Skec, S.; Storga, M.; Marjanovic, D. (2013). Mapping risks on various product development process types, Transactions of FAMENA, Vol. 37, No. 3, 1-16

[14] Kohli, R.; Krishnamurti, R. (1987). A heuristic approach to product design, Management Science, Vol. 33, No. 12, 1523-1533, doi:10.1287/mnsc.33.12.1523

[15] Steiner, W.; Hruschka, H. (2003). Genetic Algorithms for product design: how well do they really work?, International Journal of Market Research, Vol. 45, No. 2, 229-240

[16] Ayag, Z. (2005). A fuzzy AHP-based simulation approach to concept evaluation in a NPD environment, IIE Transactions, Vol. 37, No. 9, 827-842, doi:10.1080/07408170590969852

[17] Kahraman, C.; Buyukozkan, G.; Ates, N. Y. (2007). A two phase multi-attribute decision-making approach for new product introduction, Information Sciences, Vol. 177, No. 7, 1567-1582, doi:10.1016/j.ins.2006.09.008

[18] Yeo, S. H.; Mak, M. W.; Balon, S. A. P. (2004). Analysis of decision-making methodologies for desirability score of conceptual design, Journal of Engineering Design, Vol. 15, No. 2, 195-208, doi:10.1080/09544820310001642191

[19] Camm, J. D.; Cochran, J. J.; Curry, D. J.; Kannan, S. (2006). Conjoint optimization: An exact branch-and-bound algorithm for the share-of-choice problem, Management Science, Vol. 52, No. 3, 435-447, doi: $10.1287 / \mathrm{mnsc} .1050 .0461$

[20] Tsafarakis, S.; Marinakis, Y.; Matsatsinis, N. (2011). Particle swarm optimization for optimal product line design, International Journal of Research in Marketing, Vol. 28, No. 1, 13-22, doi:10.1016/j.ijresmar.2010.05.002

[21] Tsafarakis, S.; Saridakis, C.; Baltas, G.; Matsatsinis, N. (2013). Hybrid particle swarm optimization with mutation for optimizing industrial product lines: An application to a mixed solution space considering both discrete and continuous design variables, Industrial Marketing Management, Vol. 42, No. 4, 496-506, doi:10.1016/j.indmarman.2013.03.002

[22] Watts, D. J.; Strogatz, S. H. (1998). Collective dynamics of 'small-world' networks, Nature, Vol. 393, No. 6684, 440-442, doi:10.1038/30918

[23] Bemmaor, A. C.; Lee, J. (2002). The impact of heterogeneity and ill-conditioning on diffusion model parameter estimates, Marketing Science, Vol. 21, No. 2, 209-220

[24] Chou, C.-C. (2003). The canonical representation of multiplication operation on triangular fuzzy numbers, Computers \& Mathematics with Applications, Vol. 45, No. 10-11, 1601-1610, doi:10.1016/S0898-1221(03)00139-1

[25] Wilensky, U. (1999). NetLogo (http://ccl.northwestern.edu/netlogo/), Evanston 